\title{
Possibilities of closing levee breaks in flood events from the German experience
}

\author{
J. Dagher ${ }^{1}$, R. Jüpner ${ }^{1} \&$ N. Bhaskar ${ }^{2}$ \\ ${ }^{I}$ Department of Civil Engineering, University of Kaiserslautern, \\ Germany \\ ${ }^{2}$ Department of Civil Environmental Engineering, \\ University of Louisville, USA
}

\begin{abstract}
Levee breaks are responsible for immense damage to life and property, and usually cause great suffering to the people living in the area. There are a number of methods to close a levee break effectively. However, these methods are dependent on a number of factors. So far, there are limited scientific studies to determine which method of closure is most suitable for any levee that breaks. With this in mind a systematic methodology and framework is developed in this study for levee break closure. Firstly, the selection options of closing a levee break is put forward using the classification and analysis of the levee breaks closures during the floods of 2002 (resulting in 17 levee breaks) and the flood of 2013 (resulting in 11 levee breaks) in Saxony-Anhalt Germany together with the gained knowledge from literature review. Secondly, significant parameters pertaining to the geometry of the levee break, installation of the closing structure, logistics resources, and stability of the closing structure, are chosen based on the measures taken for closing the levee break. Finally, the parameters are optimized based on comparative analysis using both positive and negative results, and lessons learnt for break closing are summarized. The case study of the method discussed in this paper is based on in-depth analysis from the levee break in Fischbeck, Germany in June 2013. Barges were sunk at the break sites for the closure. The analysis of this event shows that the use of barges to close the break is a suitable choice, regarding the width of the break as well as the availability of closing structures, which led to a reduction of the inflow by $60 \%$ to $70 \%$ with the first two barges, and with the use of an additional (third) barge the inflow decreased even more. Keywords: closing a levee break, flood in Fischbeck, sinking barges.
\end{abstract}




\section{Introduction}

Floods are natural phenomena that are part of the water cycle. Man cannot control these events. Floods could be dangerous to human life, as well as create economic stress. The extreme flood in August 2002 in Saxony, Germany caused the deaths of 21 people and economic damage in the sum of 9.2 billion euros (Müller [10]). Levees are part of structural flood protection and are designed to contain floods in order to protect people and property. A failure of a levee resulting from a break (or often referred to as a breach in the US) during a flood event usually leads to catastrophic flooding that can inundate large areas originally protected by the levee. So far, there are only a few sound scientific studies which consider the specific local conditions regarding a levee break. Levee break are addressed by the European Flood Risk Management Directive (Directive [4]). The subject is covered in the brochure, "Hochwasserschutz in der DDR" which was released by the Ministry of Environmental Protection and Water Management of East Germany in 1980. This was written as a handbook for emergency managementnot as a regulation. In 2013, the "International Levee Handbook" (CIRIA [3]), within the framework of a joint venture program of England, France and the United States was published. This book deals with the function, design, construction, and maintenance of levees. A related chapter (Chapter 6.9) in the same handbook discusses the measures to close levee breaks. However, the discussion is very brief and a further work is needed in this aspect of levee disasters. Since 2007, the Department of Homeland Security of the United States has promoted a research project entitled "Rapid Repair of Levee Breaches (RRLB)" which focuses on the development of rapid closure methods for levee breaks. The initial concept development, which included small trials, was conducted in the Coastal and Hydraulics Laboratory (CHL), U.S. Army Corps of Engineers Research and Development Center, Vicksburg, Mississippi, USA. As a result, an arched rubber dam (ARCH) was developed, which represents an optimal closure method according to the test results. But the rubber dam has significant limitations stemming from geometrical aspects of the levee break such as the width of the break. This prevents a general transferability and applicability of ARCH to any levee break. There is no specific system for decision makers to determine when and how to proceed in the event of a levee break. At this time, decision makers rely on their experiences. The successful closing of a levee break depends on many parameters. The use of hydraulic or digital models is not practical because there are so many variables that are unique and different in every situation. Parameters for the selection of the technique for a break closure must be analyzed and the best solution determined will depend on these variables.

\section{Levee break analysis}

To identify the destructive potential of levee breaks, the vulnerability of the hinterland (humans, facilities etc.) must be investigated. When the hinterland is inhabited, factors such as time and material availability must be assessed to determine if closure is possible. Parameters for determining appropriate closure 
methods for a levee break include: the type of levee, the levee material, the dimensions of the levee, the breaking point, the number of fractures, the age of the structure, the cause of the break, and the bodies of water.

\subsection{Significant parameters in a levee break}

Various parameters in levee breaks need to be are analyzed. The most critical parameters to consider are:

\subsubsection{Width and depth of the levee break}

Parameters information pertaining to the geometry of the levee break consists of the width, depth, and changes of the shape of the break over time. Different break shapes will develop depending on the failure mechanism, the duration, the direction and intensity of flow through the break, and on the conditions of the levee body and subsoil. Regarding their cross sections (perpendicular to the levee's axis) the breaks are classified into three classes, each class representing a possible final stage: (a) partial damage, (b) total damage and, (c) total damage with large scours (Horlacher et al. [7]) (see Figure 1).

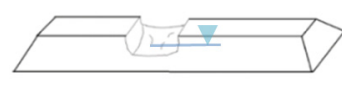

(a)

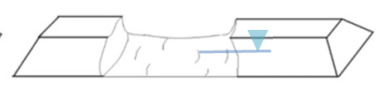

(b)

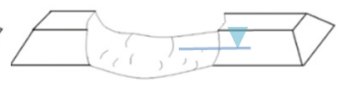

(c)

Figure 1: Types of levee break: (a) partial damage, (b) total damage and (c) total damage with large scours.

\subsubsection{Water level}

The water level parameter is the most important information if closure is being considered and is measured by studying the stream gauge at, and before, the levee break. Tensile forces occurring at the levee flanks are rising with rising water level and reach their maximum at the peak of the hydrograph. Therefore, it is important to predict the runoff pattern, focusing on the timing of the peak flow and corresponding water level. This relation especially has to be considered for multipeak flood waves. Hence, reliable information about water levels as a function of time is important when choosing the right moment for break closure.

\subsubsection{Flow velocity and shear stress}

Water behind the levee puts a lot of pressure on the surface of the levee slope. This pressure from the water is related to shear stress. In determining the closure of the levee break, consideration must be given to the shear stress because the structure for the closure must be more stable and stronger to overcome this shear stress. The water velocity and shear stress are positively correlated.

\section{Methodology}

A systematic analysis of potential and available options for effectively closing a levee break requires a comprehensive and thorough consideration of both the 
hydraulic, geotechnical, and hydro-meteorological conditions. Relevant data for the selection of the various techniques for break closure must be evaluated and the corresponding action identified for any specific case of levee break. To address this question, a methodology framework is set up (as illustrated in Figure 2). The methodology starts with the compilation of basic statistics, classification and analysis of the levee breaks and closing procedures used during the floods of 2002 involving 17 levee breaks and floods of 2013 involving 11 levee breaks in SaxonyAnhalt Germany. This analysis was further supported by the information and knowledge reported in literature on the closing levee breaks. The result was to put forward two options of closing a levee breaks, namely, the direct and indirect options. Significant parameters for the options are optimized based on comparative analysis from floods of 2002 and 2013 using geometric considerations of the levee break, installation of the closing structure and logistics, Finally, the case study based on a major levee break due to recent flooding in 2013 in Fischbeck, Germany is investigated using the above method and the lessons learnt from this are presented here.

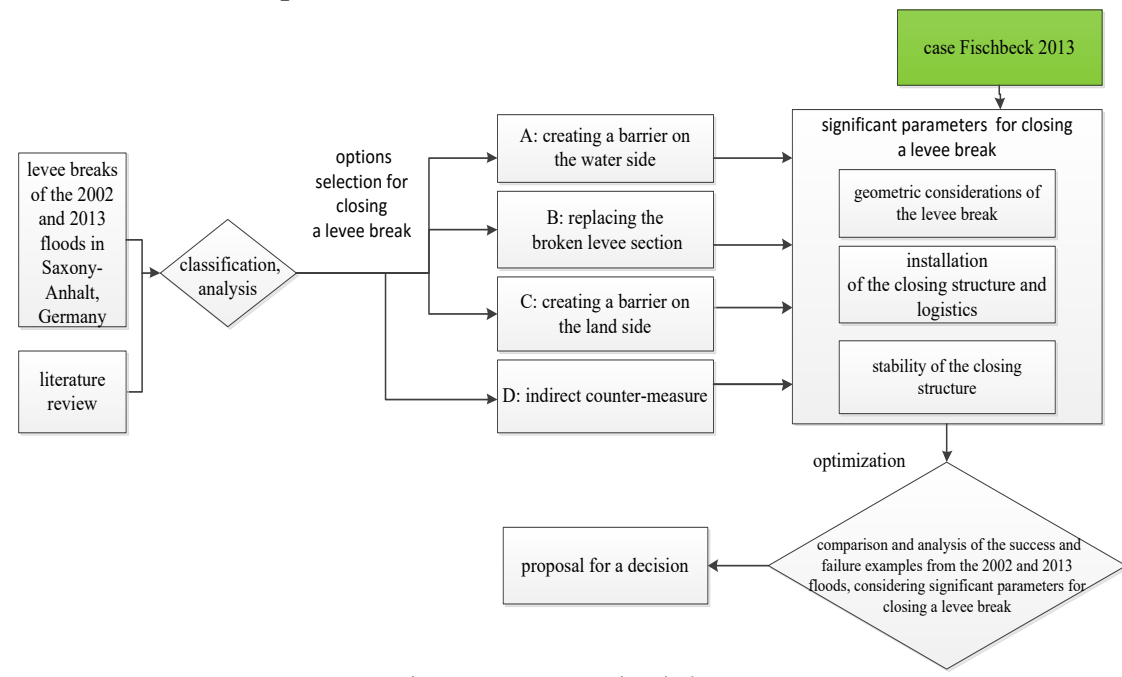

Figure 2: Methodology.

\subsection{Options selection for closing a levee break}

Basically, the counter-measures after a levee break can be either direct or indirect. The direct options include: Option A) creating a barrier on the water side, Option B) replacing the broken levee section and, Option C) creating a barrier on the land side. An indirect counter-measure may include using Option D) streets and railways to create barriers to isolate the water. This is called the second line of protection. Structures such as roads, railway embankments, natural mountain ranges, etc. should be used if possible (see Figure 3).

There are many parameters relevant to the closure of any levee break, including: hydrological parameters, the volume (or size) of the levee break (which will also determine the volume of the materials required to close the break), the 
installation of the closing structure, logistics resources, time to close, and stability of the closing structure.

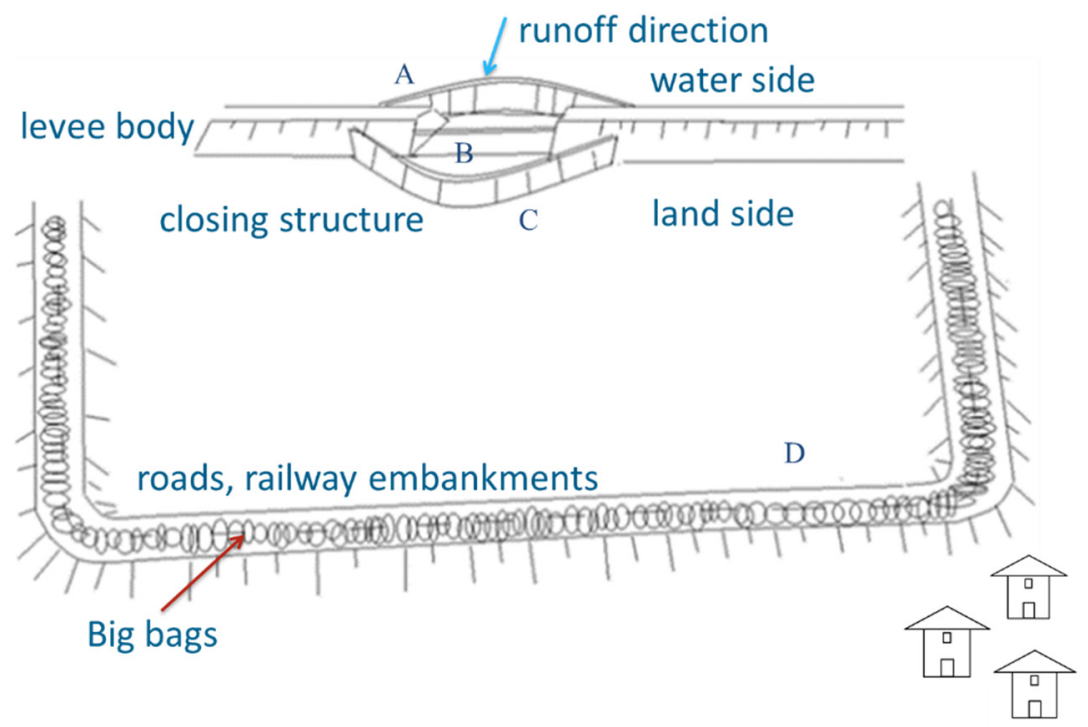

Figure 3: The direct and indirect options to close a levee break.

\subsection{Significant parameters for closing a levee break}

Choosing a method of closing a levee break is highly dependent on the available material and resources in the region/area. Therefore, cost-benefit considerations have to be performed for every location. The most important factors in determining the possibility for closure are geometric considerations of the levee break, installation of the closing structure and logistics and the stability of the closing structure. These parameters are discussed in detail below. It must be emphasized that the ultimate method used for the closure of the levee break will depend on the analysis of these parameters.

\subsubsection{Geometric considerations of the levee break}

The first consideration for closure of a levee break is to keep the break from getting bigger in order to protect the levee flanks. Knowing the width, length, and depth of the break is necessary to determine the volume of material needed for closure. Based on the results from the analysis of the closing the levee breaks and the knowledge gained from literature statistic, classification, analysis, a levee break can be categorized as follow. If the width of the levee break is less than 5 meters, it is classified as a short break. A width greater than 25 meters is classified as a wide break and a break between 5 and 25 meters is a medium break. 


\subsubsection{Installation of the closing structure and logistics}

The first step in closing the levee requires knowing where the abutments will be placed. The placement of the abutments depends on the length and stability of the closing structure. Materials for closing the levee break can be transported by: water, ship, boat, barge, dredger, by air (helicopter) and by land (truck, excavator, crane). Water transport is useful to get bulky, heavy materials to the break site. Using a helicopter has been a practical solution for floods in Germany. Factors to consider when using helicopters are capacity, how many helicopters are needed, and whether or not weather conditions will allow flights. Using land transportation is more difficult and sometimes impossible; however, it is by far best way to transport the resource to use. Materials for the closing structure are typically divided into three categories: massive, divisional (divisional is further subdivided into individual elements and overall structure), and special structure.

\subsubsection{Stability of the closing structure}

The force of the abutments and the closing structure are related with both static force and dynamic forces, such as those associated with waves, wind, and ice. To ensure the stability of the closing structure consideration must be given to the net force resulting from the horizontal hydrostatic and hydrodynamic force to the vertical force, buoyancy force of the water less the frictional force, weight of the closing structure and the force from the abutments.

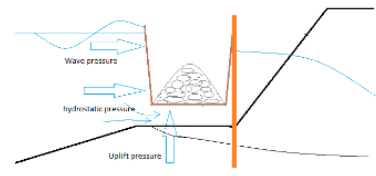

(a)

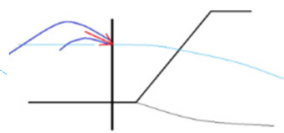

(b)

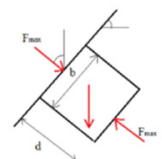

(c)

Figure 4: (a) and (b) pressure distribution of pressure relevant for structural analysis of the abutments (b) and the closing structure (a) during inservice conditions. The wave loads: (c) wave impacts after Führböter [6] and Eurotop-Manual [5].

Another important aspect of the closing materials is the stability of abutments, where the friction of the connection between ground and the abutments or the stability in ground must be enough to keep the material of closing structure in place. Before any closing structure is created, the levee flanks must be protected to prevent the break from widening. Below, three possible options for the installation of the closure section at the levee are discussed. The shear stress is considered to be equal in all three options.

Option A: the distribution of the pressure forces on the surface of the closing structure places pressure on the standing levee. This means the levee can be used as an abutment to support the closing structure (as shown in Figure 5 below).

Usually the abutments are concrete Tetrapods or tank traps. To place the abutments in the levee break, the location is chosen by the water pressure and the length of the material of the closing structure. This option tends to be the most stable of the options, but requires more materials and time to create. 


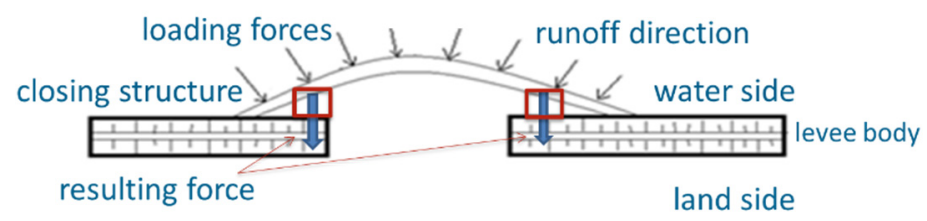

Figure 5: Option A.

Option B: as illustrated in Figure 6 below, the distribution of the pressure is perpendicular to the closing structure. The abutment must be on the land side. This option can be created in shorter time and with less material than the other options, and the levee is not used to support the closing structure.

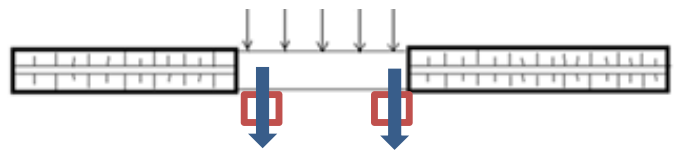

Figure 6: Option B.

Option $C$ : the distribution of pressure is solely on the closing structure (as shown in Figure 7 below). The abutments must be placed on the land side. This option is difficult to create if the water on the landside is high. In general, it is not recommended to use the levee to support the closing structures making this option less attractive. Furthermore, this option requires more time and materials to create. However, this may be the only option available if the levee break is to be fixed from the landside.

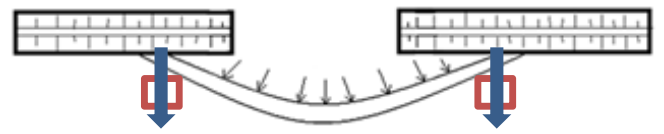

Figure 7: Option C.

Option D: Structures such as roads, railway embankments, natural mountain ranges, etc. can be used to create a barrier to isolate water after a levee break. This is called the second line of protection. This second line is created with big bags as an auxiliary levee parallel to the original levee. (Option D should begin as soon as possible after the break. There is no need to delay Option D until the crest has passed.) Experience has shown that a levee break usually cannot be closed within only a few hours, so it is important to define a possible second protection line and, at the same time, examine the other options to possible closure (Herrmann [14]).

\section{Recommendation}

Table 1 lists the options of closure and the suggested materials based on the width of the levee break.

Option $\mathrm{C}$ is used when water transportation is not possible but land transportation is possible because many materials are required and there are several abutment placements. Table 2 shows which possibilities to consider with 
the parameters present. The symbol $\odot$ represents the best option, the symbol $\otimes$ represents a poor option, and the symbol (?) represents a conditional option.

Table 1: The options of closure, possible material, necessary conditions for installation and logistics and challenges expected.

\begin{tabular}{|l|l|l|l|l|}
\hline $\begin{array}{l}\text { Geometry } \\
\text { width of } \\
\text { the levee } \\
\text { break in } \\
\text { meters }\end{array}$ & $\begin{array}{l}\text { Suggested } \\
\text { option for } \\
\text { closing }\end{array}$ & Possible material & $\begin{array}{l}\text { Necessary } \\
\text { conditions for } \\
\text { installation and } \\
\text { logistics }\end{array}$ & Challenges expected \\
\hline W $<5$ & B & $\begin{array}{l}\text { Wooden pole } \\
\text { construction, } \\
\text { electricity } \\
\text { pylons, } \\
\text { scaffolding }\end{array}$ & $\begin{array}{l}\text { Must be linked } \\
\text { together and use } \\
\text { big bags to make } \\
\text { the structure } \\
\text { massive }\end{array}$ & $\begin{array}{l}\text { Can float away if not } \\
\text { placed securely }\end{array}$ \\
\hline $5>$ W $>$ & A & $\begin{array}{l}\text { Pipeline, } \\
\text { electricity pylons }\end{array}$ & $\begin{array}{l}\text { Must be able to } \\
\text { obtain big bags to } \\
\text { make the structure } \\
\text { massive }\end{array}$ & $\begin{array}{l}\text { Difficult to transport; must } \\
\text { be floated in the water to be } \\
\text { placed }\end{array}$ \\
\hline W $>25$ & A & $\begin{array}{l}\text { Massive: barge, } \\
\text { container }\end{array}$ & $\begin{array}{l}\text { Easy to transport, } \\
\text { ability to sink }\end{array}$ & $\begin{array}{l}\text { Water could push the } \\
\text { structure out of place }\end{array}$ \\
\hline
\end{tabular}

Table 2: $\quad$ Possibilities to consider with the parameters present.

\begin{tabular}{|c|c|c|c|c|c|c|c|c|}
\hline \multicolumn{2}{|c|}{ Closing structure } & \multirow{3}{*}{ Possibility } & \multirow{2}{*}{$\begin{array}{l}\text { Water } \\
\text { level and } \\
\text { flow } \\
\text { velocity }\end{array}$} & \multicolumn{3}{|c|}{$\begin{array}{l}\text { Geometry width of the } \\
\text { levee break }\end{array}$} & \multirow{2}{*}{$\begin{array}{l}\text { Stability of } \\
\text { the closing } \\
\text { structure }\end{array}$} & \multirow{2}{*}{$\begin{array}{l}\text { Installation } \\
\text { and } \\
\text { logistics }\end{array}$} \\
\hline & & & & short & middle & wide & & \\
\hline & & & & & & & & \\
\hline \multirow{6}{*}{\multicolumn{2}{|c|}{ Massive }} & \multirow[t]{3}{*}{ Barge } & High & $\otimes$ & ( $)$ & $\theta$ & $\theta$ & $\theta$ \\
\hline & & & Medium & $\otimes$ & (8) & Q & (Q) & (1) \\
\hline & & & Low & $\otimes$ & $\otimes$ & (1) & (1) & (d) \\
\hline & & \multirow[t]{3}{*}{ Container } & High & (8) & (d) & (8) & (8) & (d) \\
\hline & & & Medium & (?) & (b) & (?) & (8) & (2) \\
\hline & & & Low & ( ) & ( ) & ( ) & (1) & (b) \\
\hline \multirow{12}{*}{ 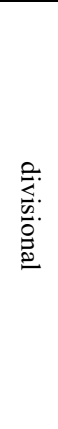 } & \multirow{6}{*}{ 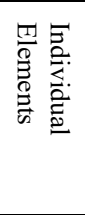 } & \multirow{3}{*}{$\begin{array}{l}\text { Wooden } \\
\text { Pole }\end{array}$} & High & (b) & $\otimes$ & $\otimes$ & (2) & (2) \\
\hline & & & Medium & (1) & (b) & (b) & (?) & (b) \\
\hline & & & Low & (1) & ( ) & (d) & (1) & (1) \\
\hline & & \multirow[t]{3}{*}{ Pipeline } & High & (?) & (8) & (?) & (8) & (8) \\
\hline & & & Medium & (8) & (b) & (8) & (8) & (8) \\
\hline & & & Low & () & ( ) & ( ) & (1) & ( ) \\
\hline & \multirow{6}{*}{ 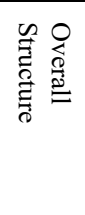 } & \multirow{3}{*}{$\begin{array}{l}\text { Electricity } \\
\text { pylons }\end{array}$} & High & (b) & (b) & (b) & (?) & (b) \\
\hline & & & Medium & (1) & (8) & (?) & (?) & ( $)$ \\
\hline & & & Low & (1) & ( ) & (1) & (1) & (1) \\
\hline & & \multirow[t]{3}{*}{ Scaffolding } & High & (1) & (b) & (b) & (8) & (8) \\
\hline & & & Medium & (1) & (8) & (8) & (8) & (8) \\
\hline & & & Low & (1) & (1) & (8) & (1) & (1) \\
\hline \multirow{6}{*}{\multicolumn{2}{|c|}{ Special structures }} & \multirow{3}{*}{$\begin{array}{l}\text { Big bags, } \\
\text { tank trap }\end{array}$} & High & $\otimes$ & $\otimes$ & (x) & $\otimes$ & $\otimes$ \\
\hline & & & Medium & (8) & (8) & $\otimes$ & (2) & (b) \\
\hline & & & Low & (1) & (2) & $\otimes$ & (?) & (1) \\
\hline & & \multirow{3}{*}{$\begin{array}{l}\text { Inflatable } \\
\text { dams } \\
\text { (RRLB) }\end{array}$} & High & (?) & $\otimes$ & $\otimes$ & $\otimes$ & $\otimes$ \\
\hline & & & Medium & (8) & ( $)$ & $\otimes$ & $\otimes$ & $\otimes$ \\
\hline & & & Low & (1) & (8) & (8) & (1) & (1) \\
\hline
\end{tabular}




\section{Example: June 2013 flood in Fischbeck, Germany}

In June 2013 the catchment area of the Elbe River was impacted by a catastrophic flood. This heavy rainfall all over Central Europe together with high early soil moisture led to the extreme flooding in Germany. As a result, the highest flood levels exceeded the levee heights at various locations along a $250 \mathrm{~km}$ length of the central Elbe and of the lower Saale Rivers (LHW [8]). On June 10, 2013 a breach in the levee in the Elbe River close to the village of Fischbeck and expanded to a final width around of $90 \mathrm{~m}$. The levee in the affected area is homogeneous and consists of cohesive material (LHW [8]). In the first few days of the levee break about 40 million $\mathrm{m}^{3}$ of water flowed into the hinterland. The discharge to the flat areas through the levee break, which was measured by means of a helicopter using an Acoustic Doppler Current Profiler (ADCP), was estimated to $500 \mathrm{~m}^{3} / \mathrm{s}$ (LHW [8]). Specific aspects of this levee break are discussed below.

\subsection{Water level}

Figure 8 below shows the recorded water levels in the Elbe River, as recorded by a stream flow gauge at Tangermunde. The peak stage occurred on June 10, 2013.

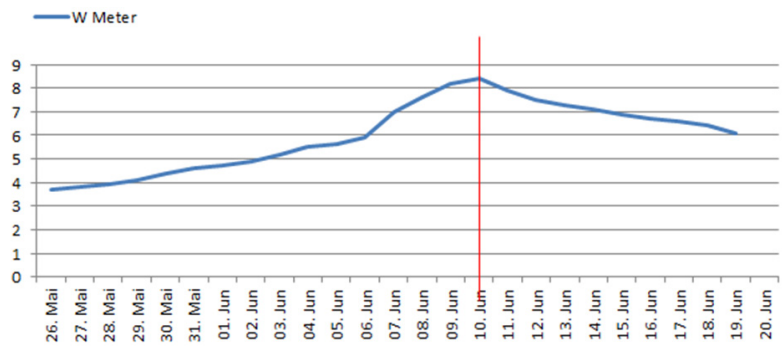

Figure 8: Hydrograph float gauge stream gauge in Tangermünde close to the village of Fischbeck (BfG [1]).

\subsection{Geometry of the levee break}

Figure 9 below describes the approximate shape of the levee breach of the Fischbeck, the maximum width of the breach was about $90 \mathrm{~m}$ (LHW [8]).

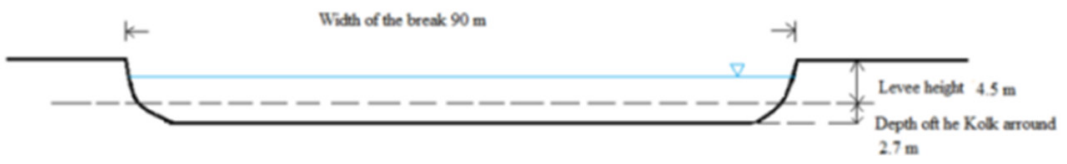

Figure 9: Width of the break and defining Kolk in the levee break of Fischbeck. 


\subsection{The steps to close the levee break in Fischbeck}

\subsubsection{First attempt}

The first attempt to close the levee break involved breaking big-bags through the shedding of these big bags from a helicopter. The big bags (constructed with a polypropylene fabric) were filled with pavement stones. The above procedure did not work

1. due to the high velocity of the water;

2. the coefficient of friction $\mu$ for polypropylene is small;

3. the big bags are not large enough to stay in place compared to the force of the water.

\subsubsection{Second attempts}

Second attempts to close the levee break with barges involved several steps as described below.

1) First helicopters dropped tank traps. The tank traps would be used to stabilize the barges during and after barge installation (see Figure 10 where plus signs are places of the tank traps) and completion of the abutment on the levee flanks by the helicopter. The journey of tugs and barges to the levee break point was difficult. After arrival, due to the large number of trafficked tons, the tug skippers had to cope with very little room and depth during the placement of the barges (Moebius [9]).

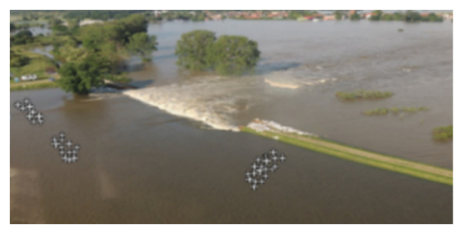

Figure 10: The placement for the tank trap abutments (picture: Juepner, 2013).

After the sinking of the barges, the Big-bags were dropped by the helicopters to secure them

2) On 16 June 2013, it was decided that a third ship be maneuvered to breaking point, because the location of the other two barges was not optimal (LHW [8]);

3) Because blasting operations are dangerous, the third barge was quickly sunk by the slotting of the side walls above the water line and subsequently loaded with big bags (Moebius) (see Figure 11(a)). Three unused barges were maneuvered to the site and sunk by demolition and cutting.

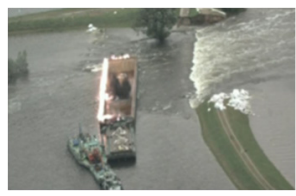

(a)

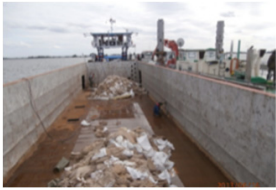

(b)

Figure 11: (a) the first barge explosion for sinking the barge (Picture: azonline.de, 2013); (b) the third barge-cutting windows in the ship to help with the sinking (picture: Moebius [9]). 


\subsection{The result}

After 9 days, initial efforts to close the break with big-bags and then with ships were partially successful by reducing the discharge through the crevasse considerably. The breach could finally be closed on June 22 after building an auxiliary levee (see Figure 12 below).

As a result of the levee break around 227 million cubic meters of water was discharged from the Elbe through the breach to the flat areas behind the levee inundating a total area of around $150 \mathrm{~km}^{2}$ between Elbe and Havel (LHW [8]). About 6000 people had to be evacuated (CEDIM [2]).

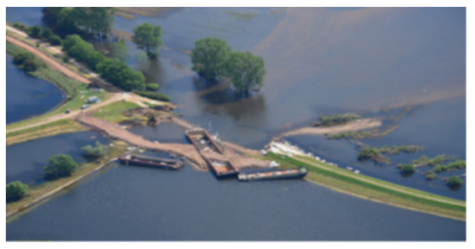

Figure 12: Levee break close of Fischbeck on June 22, 12 days after occurring. (picture: Müller, 2013).

The use of Big-bags to close the breach did not work well whenever the velocity was high, because the friction between the bags and the ground was not high enough to provide stability against the water pressure. In the future, using different materials and forms of the Big-bags could be a solution (Herrmann [14]). Using barges to close the break was a relevant choice for this kind of levee break. Given the width of the break and the availability of the barges, this method proved to be a good choice for closing the dike break. Specific reasons to support this claim include:

1. The placements for the abutments were accurate and worked well.

2. Purchasing, acquiring, and transporting the barges was fast and easy.

3. Cutting windows in the ship to help with the sinking of the barges was a good idea to lessen the danger from instability of the ships and explosions. However, this method of closing the dike break was not optimal due to the care required during its implementation. Specifically, both ends of the ship had to be sunk in the same way and the explosion was a dangerous method to use since it could potentially affect the stability of the levee and the ship. It can also cause the water to create more pressure on the levee break and cause it to get bigger.

\section{Conclusion}

This study has shown that natural disasters from levee breaks could be effectively managed. The availability of several options of levee closure and the suggested materials, as well as, the possibility for the closing structure could provide a range of benefits. The suggested options for closing levee breaks discussed in this study shows which method to consider with the parameters present and for breach mitigation. The experience in Fischbeck flood provided valuable information that can be used to examine and analyze the current methods. The closure of this levee 
break has clearly demonstrated that using the barge as structures for rapid repair of levee break is a feasible and effective option. It provides a positive motivation and momentum to move forward for future research on structural measures to close dike breaks. It also provides justification and basis for more in depth research to address the stability mechanism of the abutments and the closing structure. To this end valuable information can be obtained from advanced research currently underway on abutments and the closing structure in the field Coastal management and Breakwaters. The development of a decision support system can be a valuable tool for determining the most effective and efficient method to close a break. The system may save time and energy in trial and error attempts by giving decision makers a reference for determining the various parameters and the options that are best for meeting those criteria.

\section{References}

[1] Bundesanstalt für Gewässerkunde (BfG) (2013): Das Juni-Hochwasser des Jahres 2013 in Deutschland, BfG-1793, Koblenz.

[2] CEDIM Bericht Juni-Hochwasser (2013) Mitteleuropa, Juni-Hochwasser 2013 in Mitteleuropa -Fokus DeutschlandBericht 2.

[3] CIRIA; French Ministry of Ecology; USAECE: The International Levee Handbook, Ciria C731, London, 2013. ISBN: 978086017 734-0.

[4] Directive 2007/60/EC of the European Parliament and of the Council of 23 October 2007 on the assessment and management of flood risks.

[5] Eurotop-Manual (2007): Wave Overtopping of Sea Defences and Related Structures: Assessment Manual. In: Die Küste, Heft 73, KFKI (Hrsg.), Boyens \& Co. KG, Heidei, Holstein.

[6] Führböter, A. (1994): Wave loads on sea dikes and sea-walls. In: Abbott, M.B., Price, W. A. Coastal, Estuarial and Harbour Engineers Reference Book, London/Glasgow, England, S. 351-367.

[7] Horlacher, H-B., Bielagk, U., Heyer, T. "Analyse der Deichbrüche an Elbe und Mulde während des Hochwassers 2002 im Bereich Sachsen"; TU Dresden, Institut für Wasserbau und technische Hydromechanik, Forschungsbericht 2005/09, Dresden 2005 (in German).

[8] LHW (2014): Landesbetrieb für Hochwasserschutz und Wasserwirtschaft Sachsen Anhalt, Bericht über das Hochwasser im Juni 2013 in SachsenAnhalt. März 2014 (in German).

[9] Moebius (2014): Vortrag "Schließung Deichbruch Fischbeck" 6. Forum in Magdeburg am 27.06.2014 (in German) not published.

[10] Müller, U. "Fünf Jahre nach der Flut" - Kommentar; Wasserwirtschaft, 97(2007); Heft 7/8, Seite 3, 2007 (in German).

[11] RRLB U.S. Army Engineer Research and Development Center: Rapid Repair of Levee Breaches ERDC-CHL Coworkers: Donald Ward, Andrew Kleinman, Jimmy Fowler Oceaneering Coworkers: Brian Welsh, Michael Matalik, Phil Goodwin SERRI Southeast Region Research Initiative, National Security Directorate, June 2011. 
[12] Oumeraci, H. (2010). More than 20 years of experience using the Large Wave Flume (GWK): selected research projects. Küste 77: 179-239 In: Die Küste. Kuratorium für Forschung im Küsteningenieurwesen: Karlsruhe, ISSN $0452-$ 7739 .

[13] Oumeraci, H., Allsop, N.W.H., De Groot, M.B., Crouch, R.S., Vrijling, J.K. (1999): Probabilistic design tools for vertical breakwaters. Probabilistic design tool for Vertical Breakwaters. Final Report PROVERBS-ProyectFirst ed. University of Braunschweig, Germany.

[14] Herrmann, J. Personal communication, 19 October 2015, Deputy Head of Department Maintenance and Operations in Flood Protection and Water Management, Wittenberg, Saxony-Anhalt, Germany. 